\title{
Investigation of growth conditions, crystal structure and surface morphology of SmS films fabricated by MOCVD technique
}

\author{
N.M. Volodin***, L.V. Zavyalova*, A.I. Kirillov**, S.V. Svechnikov*, \\ I.V. Prokopenko*, A.V. Khanova*** \\ *Institute of Semiconductor Physics of NASU, 45, prospect Nauki , 252028 Kiev, Ukraine \\ **Institute of metal organic chemistry RAS, 49, st.Tropinina, Nizhniy Novgorod, 603601, Russia, 664370. \\ ***SIE named after S.A.Lavochkin, Leningradskoe shosse, 24, Khimki, 141400, Moscow district, Russia, 5755479.
}

\begin{abstract}
The polycrystalline SmS films were fabricated by MOCVD technique using a number of ditiocarbamates, synthesized by different techniques. The growth kinetics and temperature dependencies of the film growth rate are investigated, which allowed us to determine the activation energies and the reaction type. The investigations of the structure and surface morphology of films were carried out. The technological conditions are determined providing the fabrication of single-phase SmS films of cubic modification with the most ordered crystal structure.
\end{abstract}

Keyword: samarium monosulphide, structure, morphology, MOCVD-technique.

Paper received 25.06.99; revised manuscript received 09.07.99; accepted for publication 12.07.99.

\section{Introduction}

In papers $[1,2]$ we reported, for the first time, the fabrication of polycrystalline SmS films by the chemical technique and presented their main properties. The actuality of this work is caused by the fact that the $\mathrm{SmS}$ films represent an active medium for optical recording of information by laser beam due to the presence of metal-semiconductor phase transition [3]. Besides, they have an anomalous high tensosensitivity, therefore, they are used as highly sensitive tensoand baro-sensors [4]. However, prior to [1], these films were obtained exclusively by vacuum techniques, which do not provide necessary reproducibility and stability of characteristics.

The aim of further investigations is the development of the above mentioned chemical method of fabrication of samarium sulfides, based on pyrolysis of metal-organic Sm compounds. In this work the dependencies of film growth parameters and, in more detail, the crystal structure and surface morphology of films in dependence on initial substances and technological conditions are studied.

\section{Starting materials, growth conditions, film properties}

As precursors four types of initial substances were used: diethyldithiocarbamat (DTC) of samarium $\left(\mathrm{dtc}_{3} \mathrm{Sm}\right), \mathrm{dtc}_{3} \mathrm{Sm}$ bipy, $\mathrm{dtc}_{3} \mathrm{Sm}$ phen (with additional bipyridil and phenantraline ligands), obtained from the alcohol solutions in the argon ambient, and $\mathrm{dtc}_{3} \mathrm{Sm}$ obtained from aqueous solutions. First, second and third of these, used in the works [1, 2], were fabricated by the modified technique [5]. The second and third ones (with additional ligands) were fabricated for the increase of the volatility of starting substances, which is known to the increase the film growth rate. The last substance is synthesized by an original, technologically simpler technique requiring neither vacuum no inert atmosphere, the synthesis was carried out from the aqueous solutions in the air.

Experimental set-up consists of heater with heavy steel plate for temperature equalization, quartz cylinder, limiting the reaction zone, and sputtering element, mounted above the cylinder, in the center. The substrate is situated at the plate. Its temperature is controlled by thermocouple. The sputtering elements is the glass spray with the hole for a liquid with the diameter of $100-200 \mu \mathrm{m}$, the ring-shaped 
gap 50-100 $\mu \mathrm{m}$ for the flow of compressed air. Such an element provides, at the air pressure of $(0.6-1.2) 10^{5} \mathrm{~Pa}$, formation of such fine drops of the initial substance solution, that on the way to the substrate the solvent is fully evaporated from drops. As a result, the starting substance enters the substrate as the vapour mixed with the air and solvent vapour. The reaction products in this case are removed by the reversed flow along the cylinder walls through its open top part.

The films were deposited by sputtering of $0.1 \mathrm{M}$ pyridin solution of a substance onto the glass-ceramic substrates. For comparison, some samples were fabricated on substrates from monocrystalline polished silicon wafers, $\mathrm{NaCl}$ monocrystals (001) and mica platelets (0001). The substrate temperature was varied in the range from 200 to $300{ }^{\circ} \mathrm{C}$. The vast majority of samples were obtained in the stationary mode of sputtering at the intensity of the initial substance flow about $0.5 \mathrm{mg} \mathrm{cm}^{-2} \mathrm{~min}^{-1}$; several samples are obtained with keeping a small distance from spray to the substrate, i.e. at high intensity of the flow, $2.0-2.5 \mathrm{mg} \mathrm{cm}^{-2} \mathrm{~min}^{-1}$. As a result, in all investigated regimes (except of several samples fabricated using a high flow intensity), continuous uniform transparent films were obtained.

Most of fabricated films were either colorless, or with slight yellow-brown hue. At the high intensity of initial substance flow several samples were produced of dark-graybrown color which is inherent to standard polycrystalline SmS films, fabricated by thermal evaporation in vacuum and having low resistivity and high tensosensitivity. Such relatively broad range of color variation indicates its complicated and diverse composition, which can be explained by the variable valence of Sm element, changing in a broad interval, and also by the ability to form a large variety of different compounds, including those with sulfur, and by the fact

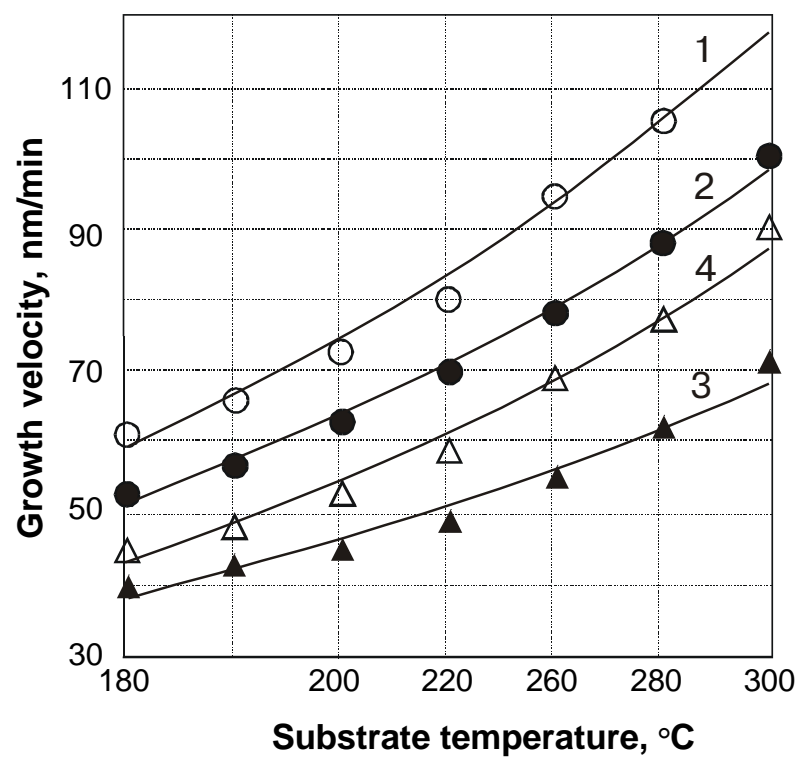

Fig.1. Dependence of film growth rate $V$ on the substrate temperature $T_{n}$ for films fabricated from different initial substances: 1- dtc 3 Sm bipy; 2- dtc ${ }_{3} \mathrm{Sm}$ phen; 3- dtc 3 Sm (waterless ambient); $4-\mathrm{dtc}_{3} \mathrm{Sm}$ (water ambient). that compound of Sm with sulfur tend to polytypism.

Fig. 1 shows the results of investigation of a substrate temperature dependence on film growth rate $V$, obtained by using different substrates. It is seen from the figure that the values of growth rate for different substances are relatively close at low temperatures. In this case the growth rate of films, obtained from substances with additional ligand (curve 1,2 ) is slightly higher. This difference is more pronounced at higher substrate temperature which is related to the increase of the substance volatility resulting in increasing the growth rate. The volatility of the substance with dipyridile ligand is the maximum for this series of substances. It is more difficult to explain the difference between curves 3 and 4 , showing that $\mathrm{dtc}_{3} \mathrm{Sm}$ obtained from the aqueous solutions has a slightly higher growth rate. It seems to be related to the degree of purity of the obtained $\mathrm{dtc}_{3} \mathrm{Sm}$ compound, namely, to what extent it is free from collateral synthesis products.

Due to a forced delivery of the starting substance to the heated substrate surface the constant concentration of the reacting materials is kept in the reaction zone. In this case the film growth rate, according to Arrhenius equation [6], depends on temperature only

$V_{I}=a_{p} \cdot \exp \left(-\frac{E_{a}}{R T}\right)$

where $V_{I}$ is the growth rate at constant initial substance flow intensity and temperature $T, a_{p}$ is preexponential factor, $E_{a}$ is the activation energy or heat of film formation process, $R$ is the universal gas constant.

Fig. 2 shows the dependence of film growth rate on substrate temperature in $\operatorname{Ln} \frac{V}{V_{0}}$ vs $\frac{1000}{T}$ coordinates. It can be seen in the figure that experimental curves can be approxi-

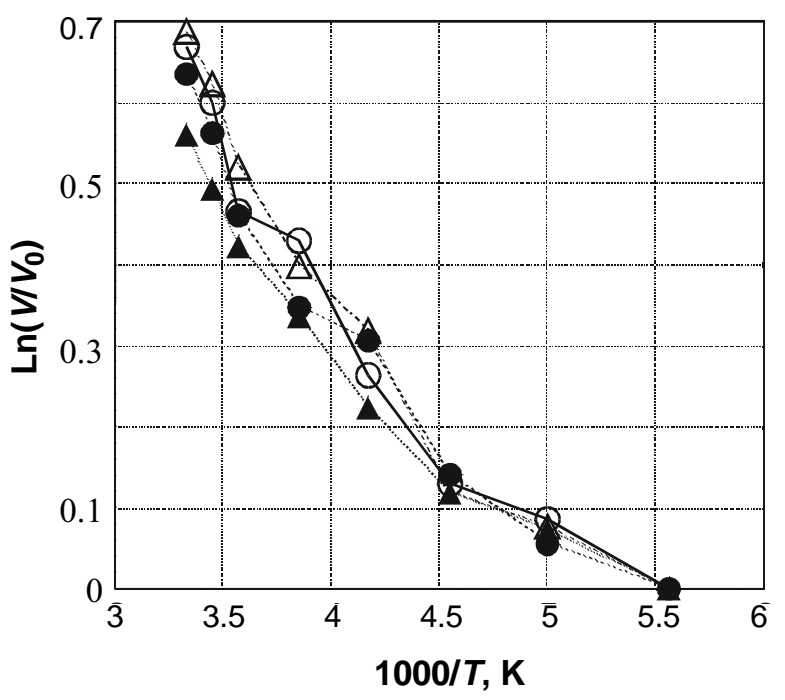

Fig.2. Dependence of film growth rate on temperature in coordinates $\operatorname{Ln} \frac{V}{V_{0}} v s \frac{1000}{T}$. 
N.M.Volodin et al.: Investigation of growth conditions, crystal structure...

Table 1. Crystal structure of SmS films in dependence on the conditions of their deposition

\begin{tabular}{|c|c|c|c|c|c|c|}
\hline $\begin{array}{l}\text { \# of } \\
\text { samp. }\end{array}$ & $\begin{array}{l}\text { Code of } \\
\text { Substrate }\end{array}$ & $\begin{array}{l}\text { Additional } \\
\text { ligand }\end{array}$ & Substrate & $\underset{{ }^{0} \mathrm{C}}{T}$ & $\begin{array}{c}I, \\
\text { mg.cm }^{-2} \cdot \min ^{-1}\end{array}$ & Crystal structure \\
\hline 15 & $9 n$ & bipy & $\begin{array}{l}\text { glass- } \\
\text { ceramics }\end{array}$ & 270 & 2.5 & Amorphous \\
\hline 31 & $11 \mathrm{n}$ & bipy & $\begin{array}{l}\text { glass- } \\
\text { ceramics }\end{array}$ & 240 & 0.5 & Polycrystal, sharp reflexes \\
\hline 32 & $11 \mathrm{n}$ & bipy & $\begin{array}{l}\text { glass- } \\
\text { ceramics }\end{array}$ & 270 & 0.5 & $\begin{array}{l}\text { Polycrystal, very sharp } \\
\text { reflexes }\end{array}$ \\
\hline 33 & $13 n$ & phen & $\begin{array}{l}\text { glass- } \\
\text { ceramics }\end{array}$ & 240 & 0.5 & Amorphous \\
\hline 34 & $7 \mathrm{k}$ & - & $\begin{array}{l}\text { glass- } \\
\text { ceramics }\end{array}$ & 240 & 0.5 & Polycrystal, sharp reflexes \\
\hline 35 & $11 \mathrm{n}$ & bipy & $\begin{array}{l}\text { glass- } \\
\text { ceramics }\end{array}$ & 200 & 0.5 & Amorphous \\
\hline 67 & $21 n$ & - & $\begin{array}{l}\text { glass- } \\
\text { ceramics }\end{array}$ & 240 & 2.5 & Polycrystal, weak reflexes \\
\hline 74 & $11 \mathrm{n}$ & bipy & $\begin{array}{l}\text { glass- } \\
\text { ceramics }\end{array}$ & 240 & 0.5 & Polycrystal, weak reflexes \\
\hline 75 & $11 \mathrm{n}$ & bipy & mica & 240 & 0.5 & Polycrystal, sharp reflexes \\
\hline 76 & $11 \mathrm{n}$ & bipy & $\mathrm{NaCl}$ & 240 & 0.5 & Polycrystal, weak reflexes \\
\hline 77 & $11 \mathrm{n}$ & bipy & $\begin{array}{l}\text { glass- } \\
\text { ceramics }\end{array}$ & 280 & 0.5 & $\begin{array}{l}\text { Polycrystal, very sharp } \\
\text { reflexes }\end{array}$ \\
\hline 78 & $11 \mathrm{n}$ & bipy & mica & 280 & 0.5 & $\begin{array}{l}\text { Polycrystal, very sharp } \\
\text { reflexes }\end{array}$ \\
\hline 79 & $11 \mathrm{n}$ & bipy & $\mathrm{NaCl}$ & 280 & 0.5 & Polycrystal, sharp reflexes \\
\hline 98 & $13 n$ & phen & $\begin{array}{l}\text { glass- } \\
\text { ceramics }\end{array}$ & 260 & 0.5 & Amorphous \\
\hline 99 & $12 n$ & bipy & $\begin{array}{l}\text { glass- } \\
\text { ceramics }\end{array}$ & 260 & 0.5 & Polycrystal, weak reflexes \\
\hline 111 & $25 n$ & bipy & $\begin{array}{l}\text { glass- } \\
\text { ceramics }\end{array}$ & 250 & 0.5 & Polycrystal, sharp reflexes \\
\hline 112 & $23 n$ & bipy & $\begin{array}{l}\text { glass- } \\
\text { ceramics }\end{array}$ & 240 & 0.4 & Polycrystal, sharp reflexes \\
\hline 122 & $12 n$ & bipy & $\begin{array}{l}\text { glass- } \\
\text { ceramics }\end{array}$ & 200 & 0.5 & Polycrystal, weak reflexes \\
\hline 123 & $12 n$ & bipy & $\begin{array}{l}\text { glass- } \\
\text { ceramics }\end{array}$ & 300 & 0.5 & $\begin{array}{l}\text { Polycrystal, very sharp } \\
\text { reflexes }\end{array}$ \\
\hline 124 & $13 n$ & phen & $\begin{array}{l}\text { glass- } \\
\text { ceramics }\end{array}$ & 290 & 0.5 & Amorphous \\
\hline $\begin{array}{l}1 \\
5\end{array}$ & \multicolumn{5}{|c|}{ standard SmS samples fabricated by vacuum technique } & $\begin{array}{l}\text { Polycrystal, very sharp } \\
\text { reflexes }\end{array}$ \\
\hline
\end{tabular}




\section{N.M.Volodin et al.: Investigation of growth conditions, crystal structure...}

mated by two linear sections in the temperature intervals from $T_{1}=180^{\circ} \mathrm{C}$ to $T_{2}=220^{\circ} \mathrm{C}$ and from $T_{1}=220^{\circ} \mathrm{C}$ to $T_{2}$ $=300{ }^{\circ} \mathrm{C}$. The activation energy is $0.26 \pm 0.15$ in the first, and $0.80 \pm 0.15 \mathrm{kcal} / \mathrm{mol}$ in the second section.

These values of activation energy correspond to the radical-type reaction [7] occurring in this case. As compared to the similar dependencies, for example, for $\mathrm{CdS}$ and $\mathrm{ZnS}$ films [8] obtained in the same way from respective diethyldithiocarbamats, the activation energy $E_{a}$ for the investigated films is much less (for $\mathrm{CdS} E_{a}=4.5 \div 15.8 \mathrm{kcal} / \mathrm{mol}$ and for $\mathrm{ZnS}$ $\left.E_{a}=5.9 \div 14.7 \mathrm{kcal} / \mathrm{mol}\right)$. This means that for the SmS films obtained from the dtc complexes the substrate temperature is rather extensive than intensive technological parameter, since in a wide range of the substrate temperature variation providing fabrication of qualitative films their growth rate changes only by a factor of 1.5-2.

\section{Crystalline structure and surface morphology of films}

The crystalline structure of films was studied by electron diffraction techniques. The investigation of the surface microrelief was carried out using scanning electron microscopy.

In Table 1 presented are the main results of crystalline structure investigation for four batches of samples obtained from 9 different initial substances, four of which are principally different from the others: one substance without an additional ligand, two substances with different additional ligands and one else - also without an additional ligand, but obtained not from the alcohol solutions in the argon ambient, as others, but from the aqueous solution.

It is seen from Table 1 that at the high flow intensity in non-steady non-equilibrium deposition regime the amorphous films or films with slightly pronounced crystalline structure are preferably created (samples \#15, 67, 68). The same low degree of structure ordering is observed at three different temperatures $\left(240,260\right.$ and $\left.290{ }^{\circ} \mathrm{C}\right)$ for films obtained from the initial substance (13n) with the additional

Table 2. SmS crystal lattice parameters

\begin{tabular}{ccccc}
\hline \hline $\mathrm{hkl}$ & $I / I_{0}[9]$ & $d, \AA[\circ]$ & $d_{1}, \AA$ & $d_{2}, \AA$ \\
\hline 111 & 55 & 3.44 & 3.33 & - \\
200 & 80 & 2.98 & 2.92 & 2.83 \\
220 & 100 & 2.11 & 2.04 & 2.12 \\
311 & 60 & 1.80 & 1.75 & 1.75 \\
222 & 55 & 1.72 & 1.66 & 1.55 \\
400 & 30 & 1.49 & 1.45 & 1.33 \\
331 & 50 & 1.37 & 1.30 & 1.25 \\
420 & 105 & 1.34 & 1.18 & 1.17 \\
422 & 105 & 1.22 & 1.11 & 1.14 \\
440 & 100 & 1.05 & 0.97 & 1.05 \\
531 & 130 & 1.01 & 0.91 & 0.99 \\
442 & 130 & 0.99 & 0.88 & 0.82 \\
\hline \hline
\end{tabular}

phenantraline ligand (samples \#33, 98, 124), which seems to be explained by the fact that phen-ligand is not separated from the dtc-complex before it strikes the substrate preventing, thus, a formation of crystallites at the surface.

For most of films obtained under stationary equilibrium conditions in the range from 240 to $300{ }^{\circ} \mathrm{C}$ at different substrates from initial substances containing the additional bipyligand, and also for both types of substances without any ligand, the polycrystalline films were obtained with the different degree of crystallite ordering. For the substrates with bipy-ligand the best structure, manifested as the most sharp reflexes in electron diffraction patterns, is observed for films obtained from initial substances which are cleaned and recrystallized before deposition.

Table 1 indicates the essential effect of the substrate material: on mica, as a rule, the crystal ordering is higher, than on amorphous glass-ceramic and monocrystalline $\mathrm{NaCl}$, which seems to be related to a definite orienting action of the (0001) surface of the mica plate.

The study of the substrate temperature effect has shown that at $T_{n}=180-220^{\circ} \mathrm{C}$ films (for example, sample \#35) are amorphous for any initial substrate. At temperature 240$260{ }^{\circ} \mathrm{C}$, as a rule, polycrystalline textured films are formed, and at temperatures $270-300{ }^{\circ} \mathrm{C}$ the most sharp reflexes (samples \#32, 77, 123) are observed on electron diffraction patterns (Fig. 3, a). This indicates the greater degree of structural ordering.

To identify the crystal structure of investigated films, in addition to data, obtained and presented in Table 1, the electron diffraction analysis was carried out of films \#1 and \#5 $(d=0.4-0.5 \mu \mathrm{m})$ deposited by thermal evaporation of polycrystalline SmS powder in vacuum onto the glass substrate using the flash evaporation technique. These films are conditionally considered as the standard samples.

In Table 2 the parameters of Sm film crystal lattice are presented: literature data [9], data for the standard sample $\# 1,\left(d_{1}\right)$ and for the investigated sample \#34 obtained from $\mathrm{dtc}_{3} \mathrm{Sm}$ synthesized in the water ambient $\left(d_{2}\right)$.

For SmS samples [9] of Fm3m-type cubic modification the value of lattice parameter $a=0.597 \mathrm{~nm}$ (semiconducting phase of $\mathrm{SmS}$ ). For the investigated samples the value of lattice parameter is essentially lower as compared to literature data and to that of the standard sample $a=0.580 \mathrm{~nm}$ and is $0.562-0.574 \mathrm{~nm}$. Within the device sensitivity no additional phase, for example, of samarium oxides or oxosulphides, was found.

Based on literature data [9], indicating that the value of lattice parameter ranges from 0.562 to $0.597 \mathrm{~nm}$, one can affirm that experimental values in the mentioned range are rather close to the theoretical values for the $\mathrm{SmS}$ metallic phase $(a=0.562 \mathrm{~nm})$ and correspond to the partial transformation of the samarium electron shell in the SmS compound.

The investigation of the film surface microrelief was carried out by scanning electron microscope «Hitachi» S-806, with magnification from $400^{\mathrm{x}}$ to $50000^{\mathrm{x}}$. Films were observed and photographed at an angle of $60^{\circ}$ (Fig. 3, b-3, f).

The films synthesized from $\mathrm{dtc}_{3} \mathrm{Sm}$ with the thickness $d=0.4 \div 0.8 \mu \mathrm{m}$ and the most perfect polycrysatlline structure (Fig. 3, b; $50000^{\mathrm{x}}$ ) have, the same as the standard sam- 
N.M.Volodin et al.: Investigation of growth conditions, crystal structure...
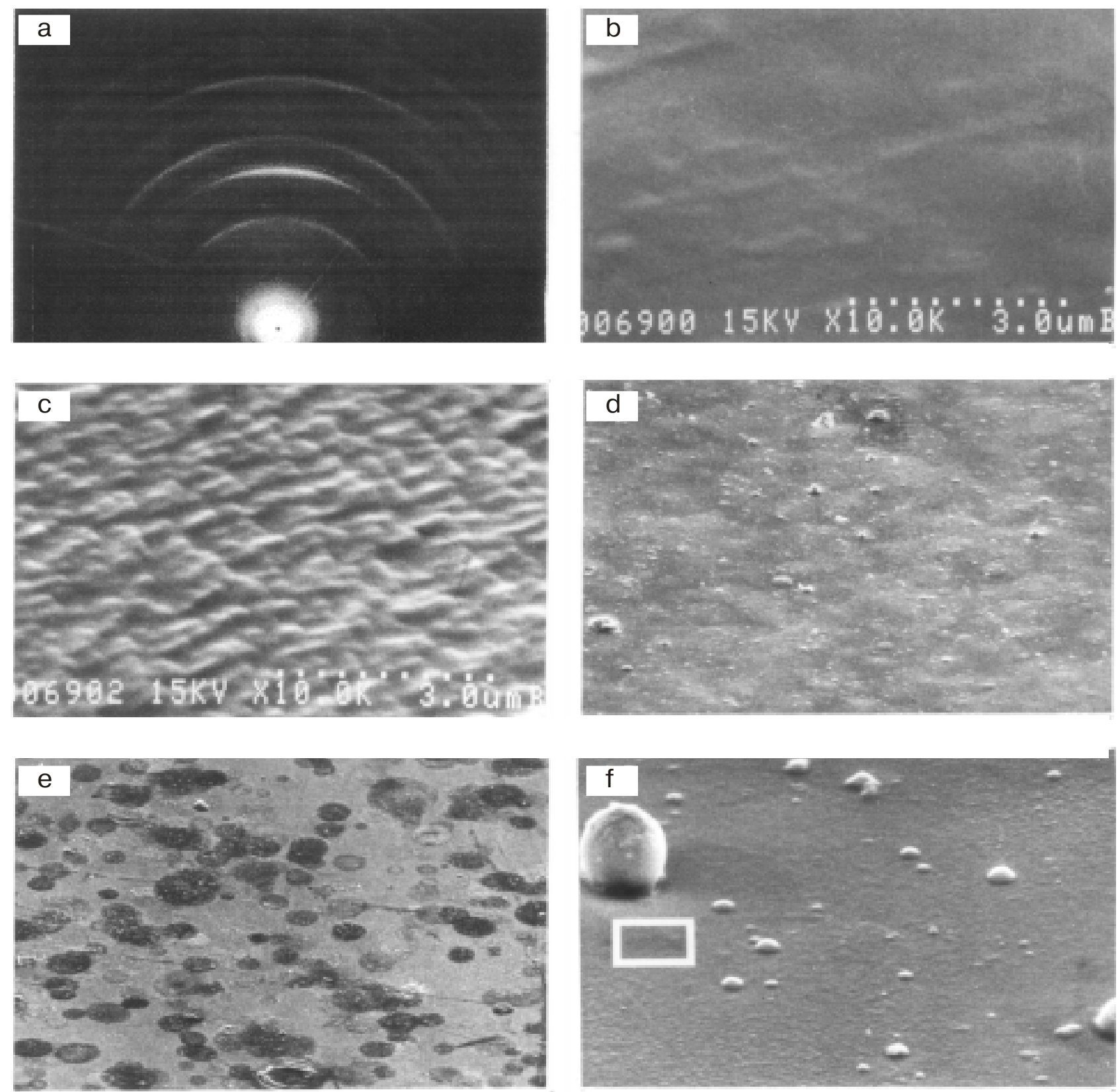

Fig. 3. Structure and microrelief of SmS film surface:

a) electron diffraction pattern for film deposited from $\mathrm{dtc}_{3} \mathrm{Sm}$ bipy with $a=0.570 \mathrm{~nm}$; b) surface microrelief of the film obtained from

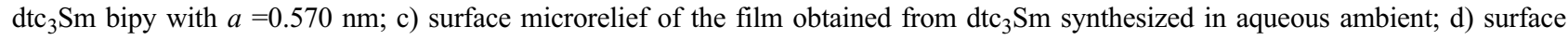
microrelief of the film obtained from $\mathrm{dtc}_{3} \mathrm{Sm}$ bipy at $200{ }^{\circ} \mathrm{C}$; e) surface microrelief of the film obtained from dtc ${ }_{3} \mathrm{Sm}_{\text {bipy }}$ at $300{ }^{\circ} \mathrm{C}$; f) surface microrelief of the film obtained from $\mathrm{dtc}_{3} \mathrm{Sm}$ phen.

ple, slightly manifested fine-grain $(10 \div 20 \mathrm{~nm})$ surface with widely situated asperities and signatures of the regular structure in the form of slightly visible parallel strips. The film obtained in identical conditions, but from $\mathrm{dtc}_{3} \mathrm{Sm}$ synthesized from the aqueous solution, has the surface microrelief in the form of fine grains with approximately equal size $(\sim 100 \mathrm{~nm})$ and signs of directed growth (Fig. 3, c; 50000 $\left.{ }^{\mathrm{x}}\right)$.

In Figs 3, d and 3, e the micrographs $\left(400^{\mathrm{x}}\right)$ are shown of the films, obtained from the same substance but at two extreme values of the substrate temperature (Table 1, sam- ples \#122 and 123). It is seen from the figures, that at temperature $200{ }^{\circ} \mathrm{C}$ at the background of a slightly pronounced relief the presence of periodically situated sharp asperities can be observed. At $300{ }^{\circ} \mathrm{C}$ they are more pronounced in the form of dark spots of the inclusion phase at the background of the main light phase.

Low-resistive films obtained in non-equilibrium conditions, i.e. at high intensity of initial substance flow, have weak adhesion to the substrate, tend to exfoliation, but within more strong sections they are continuous, uniform and large- 


\section{N.M.Volodin et al.: Investigation of growth conditions, crystal structure...}

grain: sizes of the grains ranges between 0.4 and $2.0 \mu \mathrm{m}$.

The films (\#98, 124) obtained from the substance with phen-ligand (13n), with the inherent amorphous structure, have a smooth surface - base, on which the growth of the second phase in the form of «cupolas», «spheroids» or «ellipsoids» with diameter of $2-3 \mu \mathrm{m}$ (Fig. $3, \mathrm{f}, 5000^{\mathrm{x}}$ ) is clearly visible. Comparing these films one can conclude that the initial substance, more exactly, presence and composition of additional ligand affects dramatically the microrelief of the film surface.

\section{Conclusion}

The above presented results make it possible to conclude that investigated dtc-complexes in most cases are appropriate substances which can be used as a precursors for obtaining the samarium monosulfide films using MOCVD technique. The investigation of dependence of the $\mathrm{SmS}$ film growth rate on substrate temperature, in addition to determination of activation energy, reaction type and the range of growth rate variation, allowed one to compare and estimate the quality of initial substances.

The results of electron diffraction investigations of films have shown that the degree of crystallite ordering depends essentially on the initial substance, temperature and substrate material. From the studied precursors the maximum growth rate (up to $120 \mathrm{~nm} \mathrm{~min}^{-1}$ ) and the high film quality (continuity, uniformity, polycrystallinity) is provided by samarium dithiocarbamat with bipyridile ligand. Samarium diethyldithiocarbamat without any ligand, obtained by simpler way from the aqueous solutions, provides the formation of the SmS films with the lower growth rate but with the same film quality. The most sharp reflexes at electron diffraction patterns are observed for films deposited at temperatures $240-280^{\circ} \mathrm{C}$. In this range of temperatures from the majority of substances the single-phase textured $\mathrm{SmS}$ films of cubic modification are formed with lattice parameter $a=0.562$ $0.574 \mathrm{~nm}$. Among different substrate materials the best ori- entating effect on the film structure is provided by the mica (0001) substrate. These technological parameters affect even more strongly the film surface morphology. In addition to the broad range of grain size variation (from $10 \mathrm{~nm}$ to $2 \mu \mathrm{m}$ ) observed the formation of an additional phase of the material which can not be detected by electron diffraction techniques.

\section{Acknowledgments}

The authors express their deep gratitude to professor G.A.Domrachev for valuable comments and to E.A Shchupak for synthesis of compounds.

\section{References}

1. G.A.Domrachev, L.V.Zav'yalova, S.V.Svechnikov, O.N.Suvorova, A.I.Kirillov, E.A.Shchupak. Formation of samarium sulfide films and investigation of their structure and properties. Optoelektronika i poluprovodnikovaya tekhnika, ser. 25, p.101-104 (1993).

2. L.V.Zavyalova, G. A. Domrachev, O. N. Suvorova, E. A. Shupak and G. S. Svechnikov. Samarium monosulfide films prepared from organometallic compounds. Materials Research Society, vol. 282, pp. 697 702 (1993).

3. A.I.Grachev, A.A.Kukharskiy, V.V.Kaminskiy, S.V.Pisarev, I.A.Smirnov, S.G.Shulman. Optical recording of amplitude-phase holograms on samarium monosulfide films. Pisma v ZhTF, vol.2, No.14, p.628-631 (1976).

4. V.V.Kaminskiy, I.A.Smirnov. Rare-earth semiconductors in sensors of mechanical magnitudes. Pribory i sistemy upravleniya, No.8, p.2224 (1985).

5. V.M.Byrko. Dithiocarbamats. «Nauka», Moscow, p.123 (1984).

6. B.F.Ormont. Introduction to physical chemistry and crystal chemistry of semiconductors. Moscow. «Vysshaya shkola», p.378-379 (1982).

7. V.N.Kondratiev. Kinetics of gas chemical reactions. «Khimiya». Moscow, Leningrad, p.58-60 (1958).

8. L.F.Zharovsky, L. V. Zavyalova, G. S. Svechnikov. Metalchalcogenides films prepared from chelate metal-organic compounds. Thin Solid Films, 128, No 3,4, pp.241-249 (1985).

9. S.G.Shulman, G.A.Bzhalava, E.B.Zhukova et al. Phase transition semiconductor-metal in samarium monosulfide thin films. FTT, ser. 10, p.2989-2992 (1975). 